\title{
Representation of western disturbances in CMIP5 models
}

\section{Article}

Accepted Version

Hunt, K. M. R., Turner, A. G. and Shaffrey, L. C. (2019) Representation of western disturbances in CMIP5 models. Journal of Climate, 32. pp. 1997-2011. ISSN 1520-0442 doi: https://doi.org/10.1175/JCLI-D-18-0420.1 Available at https://centaur.reading.ac.uk/79064/

It is advisable to refer to the publisher's version if you intend to cite from the work. See Guidance on citing.

To link to this article DOI: http://dx.doi.org/10.1175/JCLI-D-18-0420.1

Publisher: American Meteorological Society

All outputs in CentAUR are protected by Intellectual Property Rights law, including copyright law. Copyright and IPR is retained by the creators or other copyright holders. Terms and conditions for use of this material are defined in the End User Agreement.

\section{www.reading.ac.uk/centaur}

\section{CentAUR}

Central Archive at the University of Reading

Reading's research outputs online 


\title{
Representation of western disturbances in CMIP5 models
}

\author{
KIERAN M. R. HUNT* \\ Department of Meteorology, University of Reading, Reading, United Kingdom.
}

ANDREW G. TURNER

NCAS, University of Reading, United Kingdom; and Department of Meteorology, University of Reading, United Kingdom.

LEN C. SHAFFREY

NCAS, University of Reading, United Kingdom

\begin{abstract}
Western disturbances (WDs) are synoptic extratropical disturbances embedded in the subtropical westerly jet stream. They are an integral part of the South Asian winter climate, both for the agriculture-supporting precipitation they bring to the region and for the associated isolated extreme events that can induce devastating flash flooding. Here, WD behaviour and impacts are characterised in 23 CMIP5 historical simulations and compared with reanalysis and observations. It is found that WD frequency has a strong relationship with model resolution: higher resolution models produce significantly more WDs, and a disproportionately high fraction of extreme events. Exploring metrics of jet strength and shape, we find that the most probable cause of this relationship is that the jet is wider in models with coarser resolution, and therefore the northern edge in which WDs are spun up sits too far north of India. The frequency of WDs in both winter and summer is found to be overestimated by most models, and thus the winter frequency of WDs estimated from the multi-model mean $\left(30\right.$ winter $\left.^{-1}\right)$ is above the reanalysis mean $\left(26\right.$ winter $\left.^{-1}\right)$. In this case, the error cannot be adequately explained by local jet position and strength. Instead, we show that it is linked with a positive bias in upstream mid-tropospheric baroclinicity. Despite a positive winter precipitation bias in CMIP5 models over most of India and Pakistan and a dry bias in the western Himalaya, the fraction of winter precipitation for which WDs are responsible is accurately represented. Using partial correlation, it is shown that the overestimation in WD frequency is the largest contributor to this bias, with a secondary, spatially heterogeneous contribution coming from the overestimation of WD intensity.
\end{abstract}

\section{Introduction}

Western disturbances (WDs) are synoptic-scale (or $\alpha$ mesoscale) cyclonic perturbations in the subtropical westerly jet stream (Dimri and Chevuturi, 2016), noted in particular for their ability to bring extreme winter precipitation and flooding to Pakistan and north India (Mooley, 1957; Rangachary and Bandyopadhyay, 1987; Lang and Barros, 2004; Hunt et al., 2018c), where they are responsible for a significant fraction of the annual rainfall (Yadav et al., 2012). They exist predominantly as midlatitude vortices in the mid-to-upper troposphere, propagating eastwards (Mull and Desai, 1947), and either originating as extratropical cyclones or developing as frontal systems over Eurasia (Dimri and Chevuturi, 2014). A majority of WDs (known as 'active' disturbances) also ex-

\footnotetext{
${ }^{*}$ Corresponding author address: Kieran M. R. Hunt, Department of Meteorology, University of Reading, Reading, UK.

E-mail: k.m.r.hunt@reading.ac.uk
}

hibit notable synoptic conditions at the surface - chiefly a fall in temperature and pressure (Dimri, 2004).

WDs have been the subject of a number of modelling case studies. The first of these studies (Ramanathan and Saha, 1972; Chitlangia, 1976) showed that even early, simple models were capable of producing good approximations of the synoptic dynamics and movement of WDs. More recently, the focus of such studies has been on improvement of associated precipitation forecasts (Das, 2005; Semwal and Giri, 2007; Dimri, 2012; Semwal and Dimri, 2012; Patil and Kumar, 2016, 2017), as well as the relative importance of data assimilation (Rakesh et al., 2009; Dasgupta et al., 2004) and sensitivities to parameterisation schemes and ancillaries (e.g. orography, land surface classification) (Thomas et al., 2014; Dimri and Chevuturi, 2014; Thomas et al., 2017).

These recent studies indicate that WDs can be wellsimulated in models, however these are typically highresolution, regional models with a WD or progenitor al- 
ready in the initial conditions. Thus, we do not know how well represented WDs are in $\mathrm{GCMs}^{1}$, despite it being an important question to answer if we are to eventually consider how storms in the South Asian region are affected by future climate forcings.

At the time of writing, there exists no study that explicitly tracks western disturbances in a global climate model (or group thereof); however, a number of proxies have been used to assess how well their impact on the region is simulated in GCMs. Tiwari et al. (2014) showed that the magnitude of winter precipitation over north India across five GCMs was generally underestimated, though the distribution of extreme events was well captured. Their experiments, however, were seasonal forecasts with a onemonth lead time, and thus not strictly free-running. Conversely, Palazzi et al. (2015) demonstrated that CMIP5 models exhibit a substantial positive winter precipitation bias over the Hindu-Kush Himalaya region. Ridley et al. (2013) used a weather-regime based argument to suggest that the patterns of surface pressure associated with WDs are well simulated in a regional climate model. Objective feature tracking techniques have been used successfully in climate models for tropical cyclones (Camargo, 2013), extratropical cyclones (Zappa et al., 2013a,b), anticyclones (Purich et al., 2014), and tropical depressions (Serra and Geil, 2017; Sandeep et al., 2018). Western disturbances have a similar length scale to such systems and should, therefore, be as easily tracked - as indeed they have been in reanalysis data (Cannon et al., 2016; Hunt et al., 2018b).

Coupled Model Intercomparison Project Phase 5 (CMIP5) models are known to exhibit significant biases in summer precipitation over the Indian subcontinent (e.g. Levine et al., 2013; Sperber et al., 2013; Meher et al., 2017; Akhter et al., 2017), and the few studies on winter precipitation in the same context suggest that there are generally positive biases, particularly - as we have seen over the Himalayan foothills (Palazzi et al., 2015). Given that there is some bias over wintertime north India, and assuming that western disturbances bring most of the seasonal rainfall to the area, can the differences in their simulated and observed behaviour account for this?

In this study we will adapt the tracking algorithm of Hunt et al. (2018b) to assess the behaviour of WDs in the CMIP5 models, how and why these differ from observed features, and what the sources of intermodel variability are. This will be the first comprehensive tracking and assessment of WDs in CMIP5 global climate models.

In Sec. 2 we outline the tracking algorithm and data sources used in this study; in Sec. 3 we compare spatial and temporal distributions, both among CMIP5 models and against reanalysis; in Sec. 4 we explore the causes of intermodel variability in WD frequency; in Sec. $4 \mathrm{~b}$ we examine what causes the differences between simulated

\footnotetext{
${ }^{1}$ By GCMs here, we explicitly mean those without the benefit of data assimilation or external forcing, such as reanalyses.
}

WDs and observed ones; in Sec. 5 we investigate the relationship between simulated WDs and precipitation; finally, we conclude in Sec. 6.

\section{Methods and data}

\section{a. Global climate models}

For this study, all 23 freely-accessible CMIP5 models (Taylor et al., 2012) for which 6-hourly wind data were available were used. Temperature data were not required, as assumptions about the thermal structure of western disturbances are not made prior to tracking. Where possible, the $\mathrm{r} 1 \mathrm{i} 1 \mathrm{p} 1^{2}$ ensemble member was chosen as the representative of each model. The exception was EC-EARTH, for which, due to data availability reasons, the member r9i1p1 was used. Although most models have historical runs extending from 1850-2005, we have chosen to use only the period for which all models have available data, that is 1950-2005. The historical experiments of all models used here are forced with observed natural and anthropogenic contributions.

\section{b. Reanalysis data}

The European Centre for Medium-Range Weather Forecasts (ECMWF) interim reanalysis (ERA-Interim, Dee et al., 2011) outputs data on six-hourly timesteps, over 37 pressure levels (cf. 60 model levels), of which 27 are between 1000 and $100 \mathrm{hPa}$. It has a spatial resolution of T255, corresponding to approximately $80 \mathrm{~km}$ at the equator, and spans from 1979 to the present day. Data from ships, buoys, satellites, and sondes are assimilated. A full catalogue of WD tracks in ERA-Interim has already been produced (Hunt et al., 2018b) and is freely available online $^{3}$. In this study, we will compare ERA-I WD tracks with CMIP5 WD tracks, though we must re-compute the former so that the methodology is consistent (see Sec. d). To do so, we use vorticity data for the whole output period (1979-2017) at six-hourly intervals.

\section{c. Observational data}

The Asian Precipitation-Highly Resolved Observational Data Integration Toward Evaluation of Water Sources (APHRODITE; Yatagai et al., 2009, 2012) is a gridded, gauge-based precipitation product, available at daily timesteps and a resolution of $0.25^{\circ}$, covering the period 1951-2007. In terms of continuity and gauge density, it is one of the best precipitation products available over South Asia (Prakash et al., 2015), and performs well against satellite-based products (Guo et al., 2015). We will use this as our "observed" precipitation when comparing

\footnotetext{
${ }^{2}$ i.e. first (r)ealisation, first (i)ntialisation, first (p)hysics setup

${ }^{3}$ http: //catalogue.ceda.ac.uk/uuid/

f66c26bcf 7684 ed29d14a88825884a19
} 
real to modelled WD rainfall attribution and when looking at winter precipitation biases in the region.

\section{d. Tracking WDs in CMIP5 data}

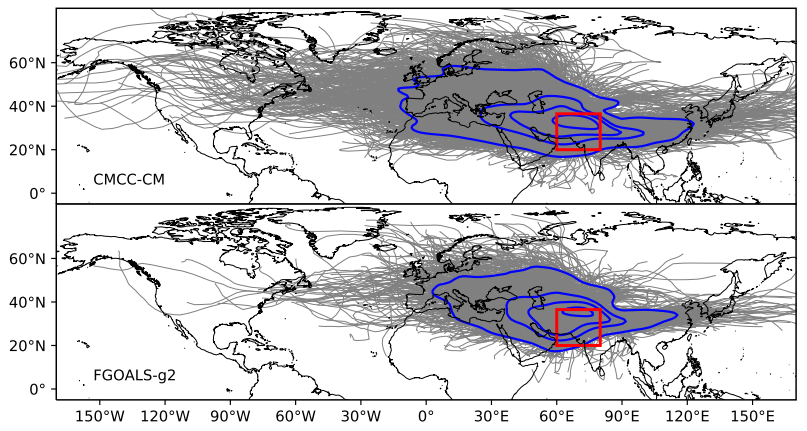

FIG. 1. WD tracks for two of the CMIP5 models used in this study. CMCC-CM has the longest mean track (7058 km), and FGOALS-g2 the shortest $(5815 \mathrm{~km})$. Blue contours mark track point densities of $0.1,0.5$, 1 , and 2 year $^{-1}(100 \mathrm{~km})^{-2}$ respectively. The domain through which all tracks must pass is marked by the red box.

Objective feature-based (i.e. parcel-following) tracking of western disturbances has recently been performed on reanalysis data with a view to exploring the structure and variability (Hunt et al., 2018b). We use that algorithm here, with a few modifications. For the reader's convenience, the entirety of the algorithm, including the necessary changes for use with CMIP5 output, is given below.

1. Compute the six-hourly relative vorticity at $500 \mathrm{hPa}$. In previous work with reanalysis data, the 450$300 \mathrm{hPa}$ mean vorticity was used; however CMIP5 six-hourly output is available only (for this part of the troposphere) at 500 and $250 \mathrm{hPa}$. Sensitivity tests carried out with reanalysis data indicated that $500 \mathrm{hPa}$ was a suitable replacement, the cost being a slightly shorter average track. Since we are not particularly interested in the genesis/lysis regions, this is an acceptable compromise.

2. Truncate the vorticity field at a spectral resolution of T63 ( $\sim 200 \mathrm{~km}$ at equator). We shall call this quantity $\xi$. There are several advantages to this step: firstly, the orography of the region generates some noise in the mid-tropospheric vorticity field through gravity wave production, spectral truncation filters this out due to its comparatively small spatial scale; secondly, this resolution is coarser than most CMIP5 models and thus quickly eradicates effects caused by improved resolving power. We state the caveat that resolved physical processes in the model, as well as the upstream Zagros Mountains, are still affected by resolution and as a result there will be components of vorticity tendency sensitive to the underlying grid scale that will not be mitigated by this preprocessing.
3. Locate all local maxima in $\xi$ subject to some radius $\delta$, such that a point is considered a local maximum if no points with a distance $\delta$ have a greater value of $\xi$. We shall call this set of local maxima $\chi_{i}$.

4. For each $\chi_{i}$, associate local positive nonzero values of $\xi$ and integrate to find the centroid of $\xi$ for each. We shall call this set of points $X_{i}$.

5. (a) To group the candidate points into tracks: for each $X_{i}$ at time point $j$, seek and attach the nearest neighbour from time point $j+1$, so long as it is within some distance $\Delta$, using the $k d$ tree nearest neighbour algorithm (e.g. Yianilos, 1993).

(b) The efficacy of this step can be increased by introducing the concept of a background velocity, important when considering the highfrequency, high-velocity nature of WDs. Here this is done by biasing the search radius using the contemporaneous wind field; for example, in a wind field, $\mathbf{u}$, the central location from which the nearest neighbour is sought is not $X_{i}$ but $X_{i}+\mathbf{u}\left(X_{i}\right) \cdot\left(t^{j+1}-t^{j}\right)$. Simply put, rather than starting the nearest neighbour search at the location of the candidate point at the previous time-point, we assume it is advected by the background winds and start the search from the location where it would have ended up after such advection.

6. We also hold the tracks in memory for one time point, looking for a candidate in time point $j+2$ within $2 \Delta$ of $X_{i}$. This prevents breaking a track into two pieces unnecessarily in the event of a candidate apparently disappearing for a single time-point.

7. These resulting tracks are then filtered three times. Firstly, "stubs" of length shorter than two days are rejected. Secondly, tracks that do not pass through Pakistan or north India, defined as $20-36.5^{\circ} \mathrm{N}, 60$ $80^{\circ} \mathrm{E}$ (see Fig. 1), are rejected as not of interest to this study. Thirdly, tracks whose geneses are east of their lyses and thus do not propagate eastwards are rejected. Finally, disturbances with a genesis east of $60^{\circ} \mathrm{E}$ are filtered out - this serves to remove contamination from mid-tropospheric cyclones that spin up during the summer monsoon as well as expunging any vortices that might arise from Hindu Kush and Himalaya lee cyclogenesis.

8. The values of $\delta$ and $\Delta$ were determined empirically in Hunt et al. (2018b) by running the algorithm over 19 case studies identified from previous literature and choosing the combination giving the closest match in the ERA-I reanalysis. These were found to be $850 \mathrm{~km}$ and $1000 \mathrm{~km}(6 \text { hours })^{-1}$ respectively. 
We cannot be certain that tracking vorticity maxima in this region will yield only WDs or WD-like disturbances without further analysis. Such analysis was completed by Hunt et al. (2018b) (see Fig. 9 therein) who applied a $k$-means clustering method to a multi-field composite of tracked systems. They found the first order of variance to be intensity (i.e. the magnitude of the fields), and the second order to be wavelength. Had a different type of system contaminated the database, then the first order of variance would have been structural; that not being the case, we can be sure that such impurity is negligible.

For illustration, the tracks of the two models with the shortest and longest mean track lengths (FGOALS-g2 and CMCC-CM respectively) are given in Fig. 1.

\section{Frequency and spatial distribution}

\section{a. Frequency}

We start by comparing the WD frequencies of each model for both winter (DJFM) and summer (JJAS) seasons $^{4}$. Frequency is computed on a daily basis - from which coarser statistics can be derived - by counting the number of tracks intercepting the Pakistan-north India domain (given in red in Fig. 1).

These are given as violin plots in Fig. 2, with results from ERA-Interim for comparison. In winter, the CMIP5 multi-model mean of 30.4 season $^{-1}$ is 0.64 standard deviations above the ERA-I frequency of 26.9 season $^{-1}$; in summer, the CMIP5 multi-model mean (MMM) ${ }^{5}$ of 4.8 season $^{-1}$ is 1.17 standard deviations above the ERAI frequency of 2.9 season $^{-1}$. Comparing the shapes of the distributions by looking at higher-order moments, the ERA-I variances are not significantly different from the distribution of individual model variances for either season; however, the skewness does significantly differ in both cases: for winter and summer respectively in ERA-I, the skewnesses are 0.66 and 0.42 , compared with MMM values of 0.05 and 0.35 . In other words, the models tend to underestimate the relative thickness of the right tail of the seasonal frequency distributions. For both seasons, the mean intra-model variance ${ }^{6}$ and inter-model variance were not statistically separable, and we thus cannot make any confident claims on how consistently WDs are represented across the CMIP5 models; only that when compared to reanalysis, the models do generally well except for a slight - though not universal, three models underestimate summer frequency and five winter - overestimation of frequency and inability to capture the asymmetries of the seasonal histograms.

\footnotetext{
${ }^{4}$ WDs are typically at their most numerous and most intense during the winter months, whereas those that do occur during the summer months, whilst unusual, can be extremely devastating due to their constructive interaction with the monsoon.

${ }^{5}$ To clarify, we define multi-model mean as the simple average of the first ensemble member (unless otherwise stated) for all valid models.

${ }^{6} \mathrm{By}$ this, we mean the interannual variance for a given model.
}

\section{b. Spatial distribution}

Fig. 3(a) shows the distribution of WD track genesis points in ERA-Interim and the difference with the CMIP5 historical MMM; these are each computed by applying a spherical kernel density estimate to the set of all track geneses. The overestimation in WD frequency shown in Fig. 2 is again clear, but the spatial pattern is otherwise generally well represented, except for a slight underestimation of the eastward and southward extents. Extending this to all track points, in Fig. 3(b), we see again that although the spatial extent is generally well represented, the signal from the frequency overestimate is clear. Furthermore, there is a significant eastward extension of the tracks in CMIP5 compared with ERA-Interim, indicating that the GCM WDs tend to penetrate more deeply across the subcontinent and into the central Himalaya. Most of the intermodel variance in these fields is controlled by variation in frequency rather than location.

\section{c. Relationship with modes of internal variability}

It has been shown that western disturbances tend to (though not exclusively) feed off baroclinic instabilities (Hunt et al., 2018a), hence their typically baroclinic structure (Hunt et al., 2018b). A simple way to indicate this is demonstrated in Fig. 4 - we take the 'baroclinic angle', that is to say the local angle between the density and pressure isosurfaces which can be computed directly using $\nabla \rho \times \nabla p$, which is proportional to the baroclinic term in the vorticity tendency equation (Holton and Hakim, 2012) - and correlate its monthly means with the western disturbance monthly frequencies. CMIP5 daily field outputs have a fairly limited vertical resolution, and we have altered the ERA-Interim calculations to reflect that (using levels at 850, 700, 500, 250, and $100 \mathrm{hPa}$ ). Fortunately, this degradation introduces errors in magnitude not exceeding $15 \%$ in the domain of interest.

The value of the correlation coefficient between baroclinic vorticity tendency and WD frequency in ERAInterim is given in Fig. 4; computed interannually using data from the winter months (DJFM, 1979-2016). This is computed at two levels: $500 \mathrm{hPa}$ (Fig. 4(a)) and $250 \mathrm{hPa}$ (Fig. 4(a)). At $500 \mathrm{hPa}$, there is a large area of significantly positive correlation, centred over the Persian Gulf; at $250 \mathrm{hPa}$ this is reduced in size and intensity, and is translated poleward, over Iran. This corroborates previous findings that WDs lean poleward with height, that they have a vorticity maximum near $500 \mathrm{hPa}$, and that they seem to intensify rapidly on approach to the Hindu Kush and Karakoram (Hunt et al., 2018b).

Figs. 5(a) and 5(b) show the CMIP5 (historical) multimodel mean values of the interannual correlation coefficient at $500 \mathrm{hPa}$ and $250 \mathrm{hPa}$ respectively. These are computed in the same way as they were for ERA-I for each model, except for different dataset lengths, with the mean 


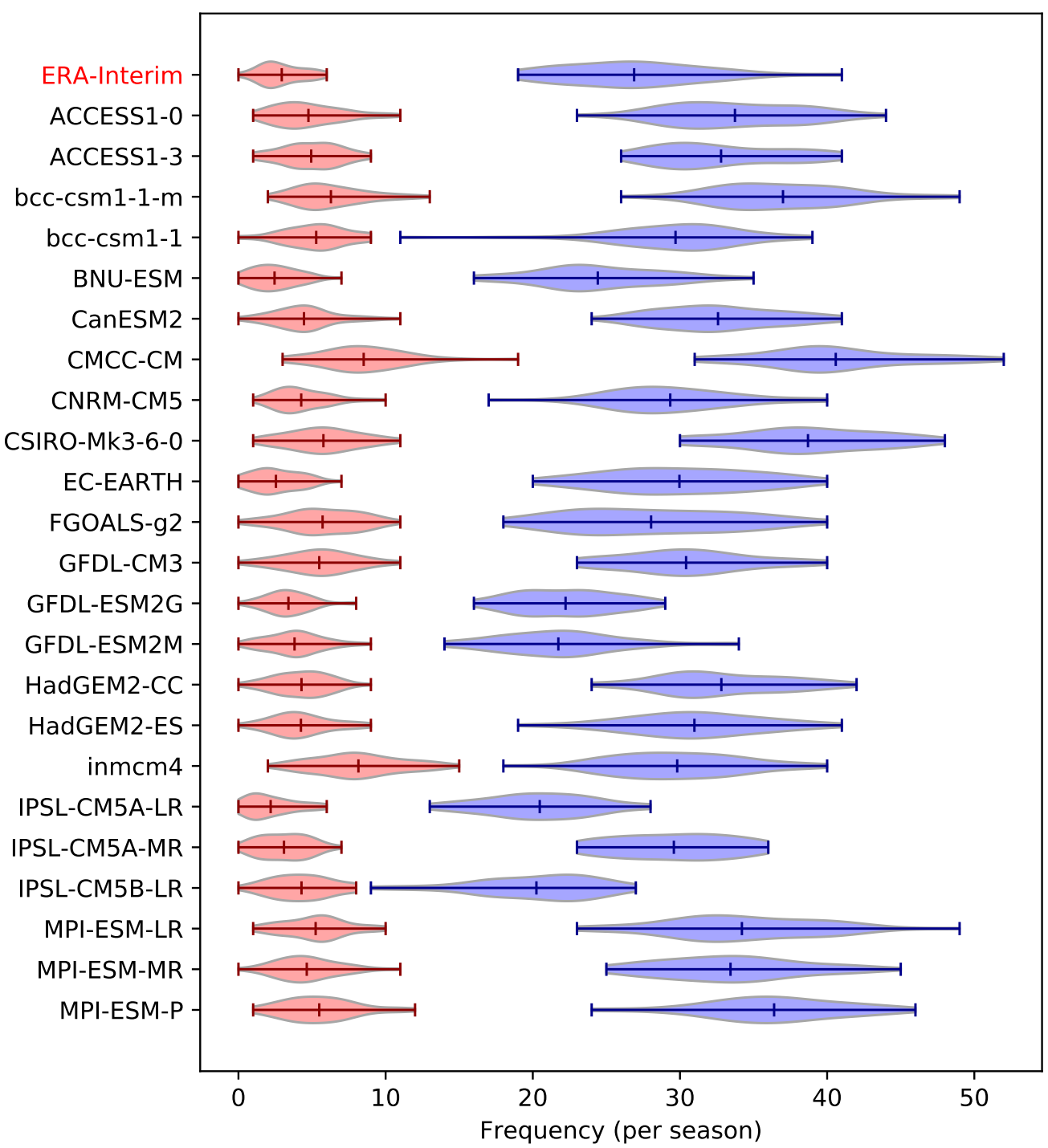

FIG. 2. Violin plots denoting the estimated density functions for annual frequencies of western disturbances in each of the 23 CMIP5 historical experiments used in this study, separated by season: Dec-Mar in blue, and Jun-Sep in red. Bounds indicate the extrema, with the central ticks indicating the means. The equivalent functions for ERA-Interim are given at the top.

of the results given here. The results are broadly the same as in Fig. 4, albeit slightly reduced in magnitude: a large area of significantly positive correlation located roughly over the north Arabian Sea at $500 \mathrm{hPa}$, which at $250 \mathrm{hPa}$ shrinks and migrates poleward (and westward). These similarities strongly imply two key results: firstly that the structures of WDs in CMIP5 models are close to those in reanalysis, although this cannot be demonstrated directly due to the limited vertical resolution of the output from the former; and secondly that the processes governing development and subsequent intensification are also well represented. Note also that at $500 \mathrm{hPa}$ (Figs. 4(a) and 5(a)), the areas of highest correlation are co-located with the regions of highest track genesis density in Fig. 3(a).

\section{Causes of intermodel variability}

\section{a. Resolution}

Horizontal resolution has been shown to be an important control in tropical cyclone frequency and intensity in GCMs (Roberts et al., 2015); though work on CMIP3 models has suggested that this is likely down to the local vorticity tendencies rather than larger-scale progenitors (Walsh et al., 2013). The relationship of model resolution with frequency or intensity of mesoscale or synopticscale systems in the vicinity of the Indian subcontinent has not been explored in depth, though it has recently been shown that higher model resolution leads to increased in- 


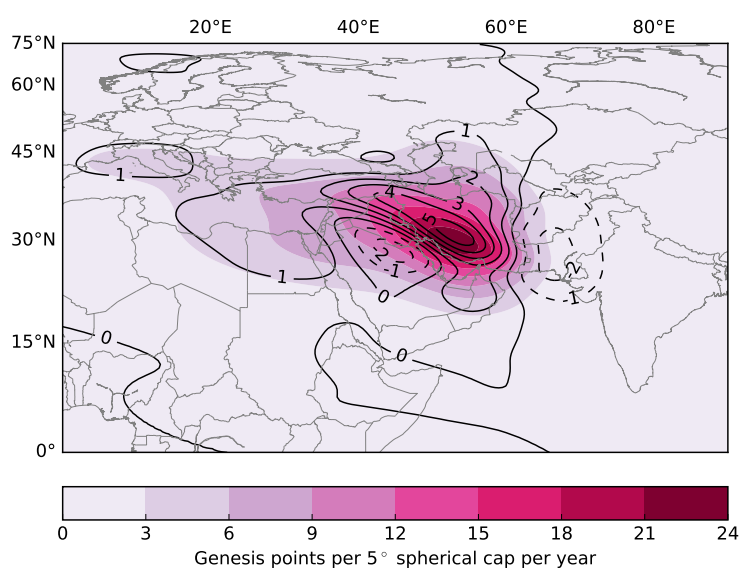

(a) genesis density

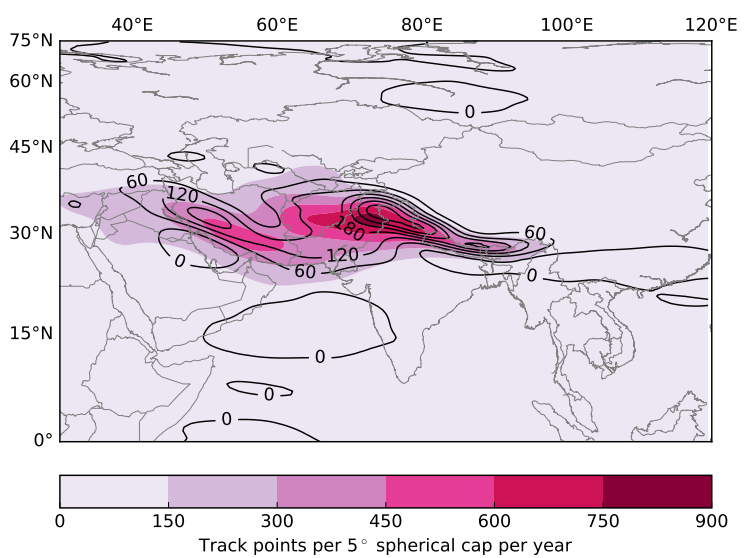

(b) track density

FIG. 3. Spherical kernel density estimates [year ${ }^{-1}\left(5^{\circ} \text { spherical cap }\right)^{-1}$ ] for (a) track genesis points and (b) all track points. CMIP5 multi-model mean densities given in coloured contours; the difference (CMIP5 minus ERA-I) in line contours.

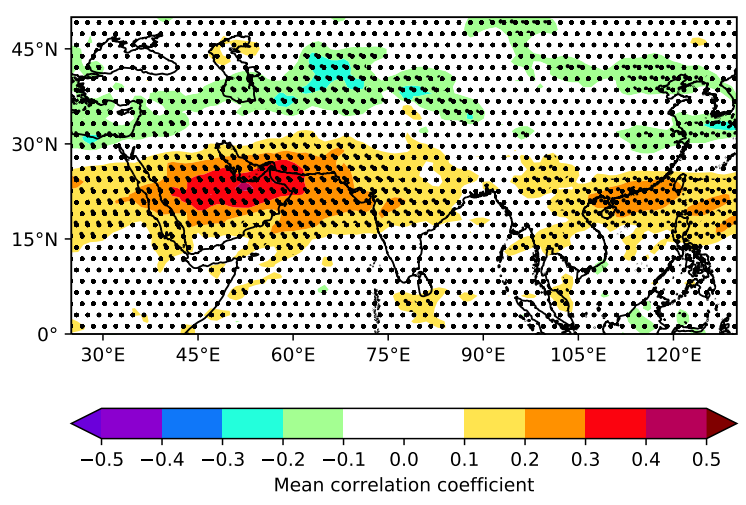

(a) $500 \mathrm{hPa}$

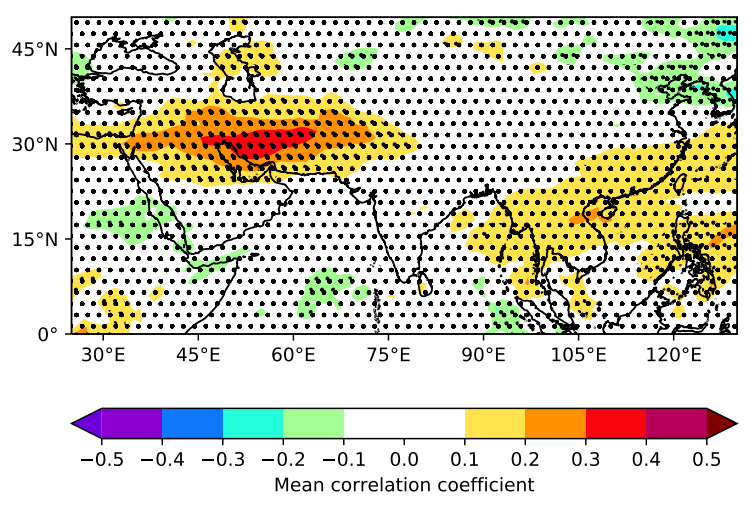

(b) $250 \mathrm{hPa}$

FIG. 4. Interannual correlation coefficients between the monthly mean baroclinic angle at (a) $500 \mathrm{hPa}$ and (b) $250 \mathrm{hPa}$ and the monthly western disturbance frequency, computed using ERA-Interim, December - March. The reanalysis data were coarsened to match the available vertical resolution from the CMIP5 output, so that calculations based on vertical gradients were consistent. Stippling indicates where the correlation coefficient was significant at the $90 \%$ confidence level. Note that the colour scales differ between here and Fig. 5 .

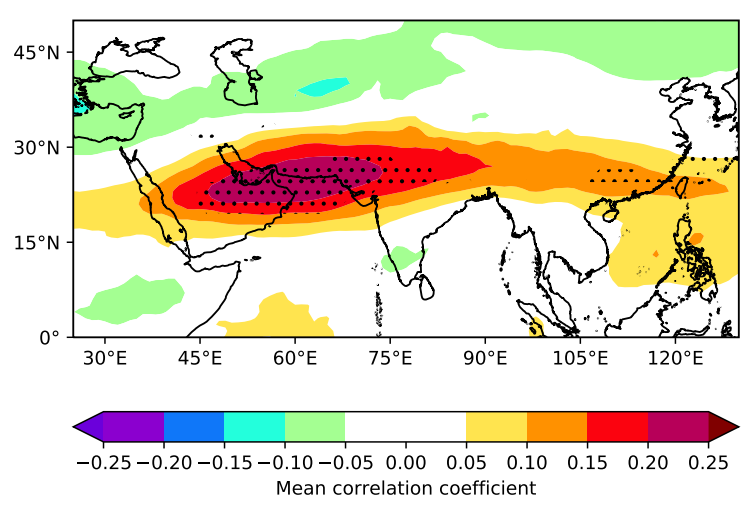

(a) $500 \mathrm{hPa}$

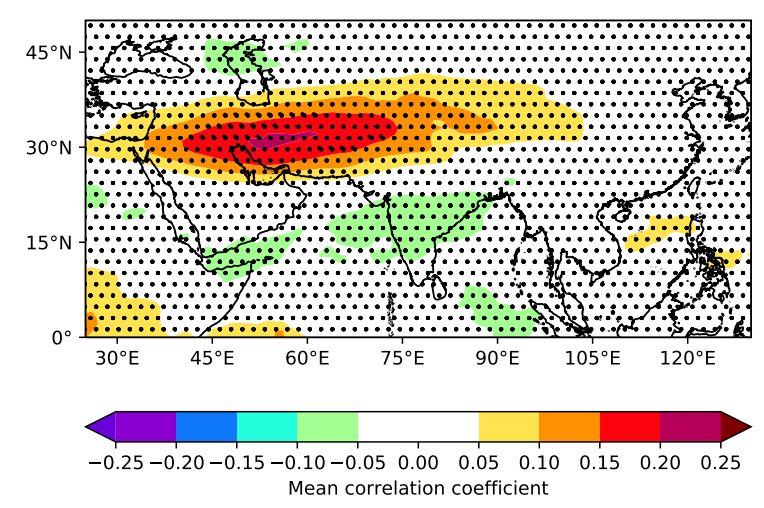

(b) $250 \mathrm{hPa}$

FIG. 5. As Fig. 4 but instead showing the multi-model mean of correlations computed for each CMIP5 model. Stippling indicates where at least half of the models had a correlation coefficient that was significant at the $90 \%$ confidence level. Computed for December - March. 


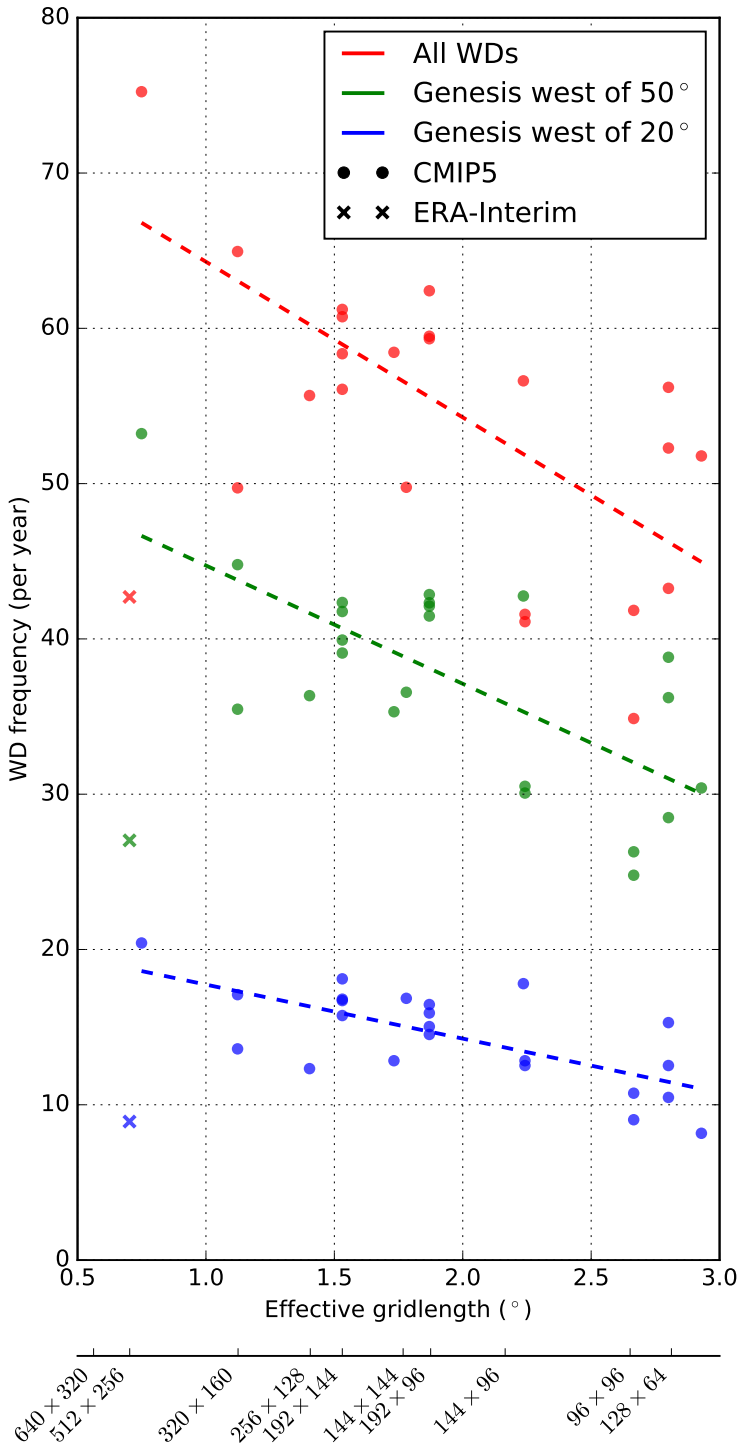

(a) genesis

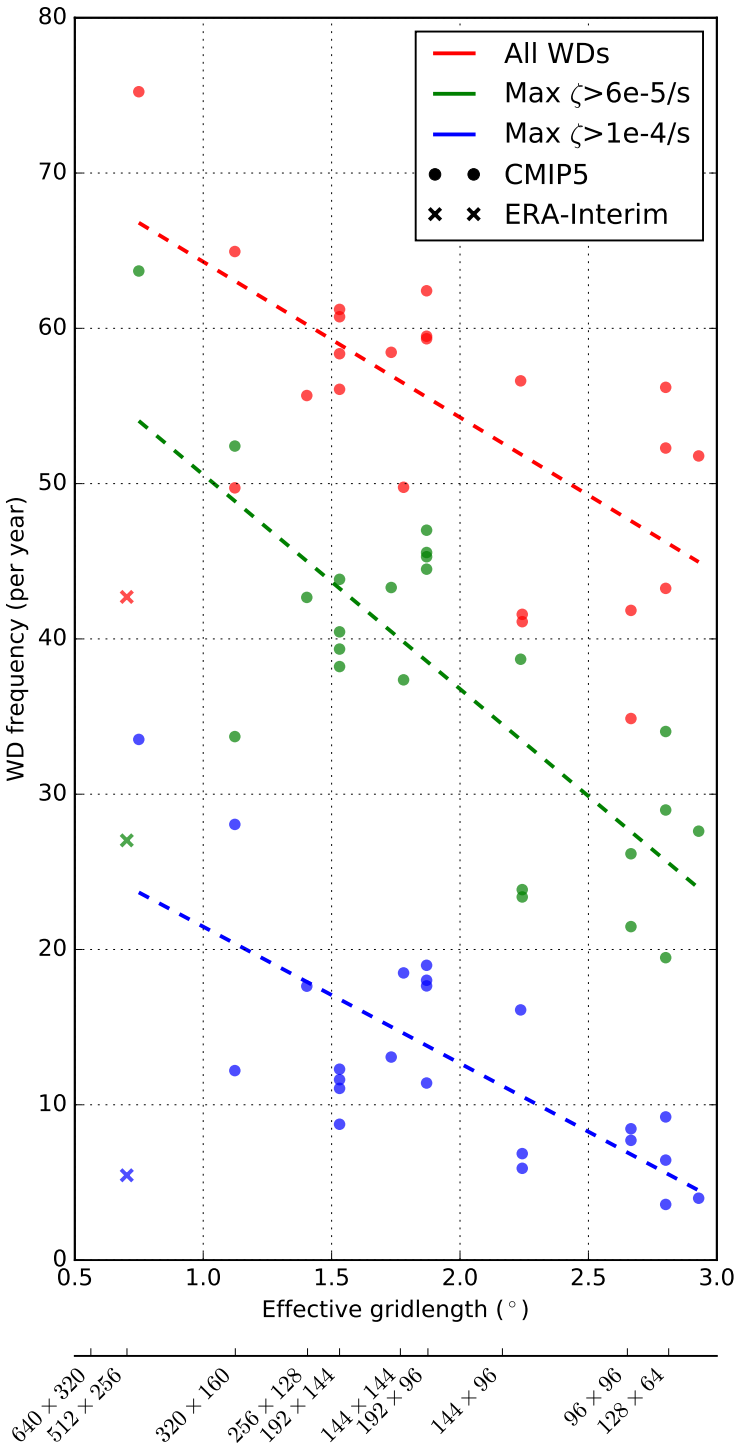

(b) intensity

FIG. 6. Mean WD frequency as a function of resolution, subset by thresholds in (a) genesis longitude and (b) peak intensity, computed using $500 \mathrm{hPa}$ truncated vorticity. Effective gridlength is defined as the geometric mean of the longitude and latitude spacings. Popular resolutions are provided for reference on the additional abscissa. Values for ERA-Interim are denoted by crosses for each case.

tensity and track length of monsoon depressions in an NWP framework (Hunt and Turner, 2017).

The intermodel relationship between resolution and tracked WD frequency is shown in Fig. 6. There is a clear correlation between the two: increasing resolution is associated with a significant increase in WD frequency; for example, a linear regression suggests that decreasing the effective gridlength from $3^{\circ}$ to $1^{\circ}$ will raise the average frequency of simulated WDs from 45 year $^{-1}$ to 65 year $^{-1}$. The correlation coefficient across all WDs with resolution (i.e. the red lines in Fig. 6) is -0.68. Fig. 6(a) shows how this relationship changes for subsets of events whose gene- ses are west of $50^{\circ} \mathrm{E}$ and $20^{\circ} \mathrm{E}$ respectively. The relative slope (i.e. gradient over absolute value) does not vary significantly across the three categories, and thus the null hypothesis that resolution has no bearing on upstream genesis longitudes cannot be rejected.

In contrast, Fig. 6(b) shows that there are strong variations in slope between the three threshold categories, when using peak intensity ${ }^{7}$. Here, the trendline gradients do

\footnotetext{
${ }^{7}$ Here, we define peak intensity as the largest value of T5-T63 spectrally-bandpassed $500 \mathrm{hPa}$ relative vorticity ${ }^{8}$ achieved by a western disturbance when over Pakistan or India. This has been shown to be a good proxy for rainfall (Hunt et al., 2018b).
} 


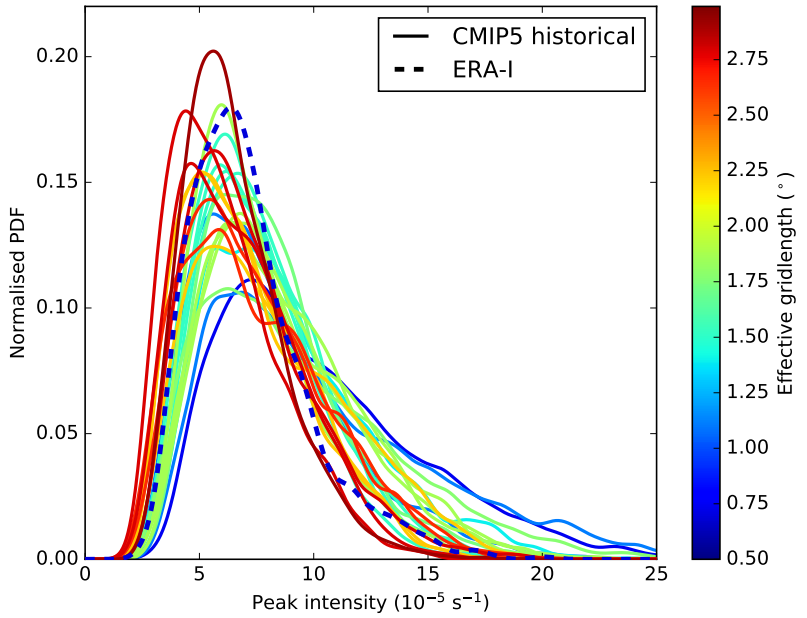

FIG. 7. Probability density functions for peak WD intensity - measured using the $500 \mathrm{hPa}$ relative vorticity, as in Fig. 6(b) - for each model (solid) and ERA-Interim (dashed), coloured by model resolution.

not decrease relatively with increasing thresholds. Instead, they suggest that higher resolution models are more likely to spawn higher intensity WDs. As previously mentioned, decreasing the effective gridlength from $3^{\circ}$ to $1^{\circ}$ will raise the annual frequency of all WDs by about $40 \%$, but will raise the frequency of the strongest WDs - those which reach a mid-tropospheric vorticity exceeding $10^{-4} \mathrm{~s}^{-1}$ by about $450 \%$. This result is similar to that previously found for tropical cyclones, which indicate that there are preferential increases in the most intense storms with resolution (e.g. Roberts et al., 2015).

The relationship between resolution and peak intensity can be quantified further by looking at the probability density functions in Fig. 7. The CMIP5 models, whose individual PDFs are given by the solid coloured lines, show a marked shift with increasing resolution: both the mean and median increase by over $50 \%$ across the range, though perhaps more importantly, the right tail exhibits a strong sensitivity to resolution. This suggests that higher-resolution models are capable of regularly simulating WDs with intensities three to four times higher than the median, which is very different to the statistics of ERA-I WDs.

It is clear that resolution is responsible for a great deal of the intermodel variance in WD frequency; now, we consider what mechanism might cause increased resolution to spawn more WDs. It has been shown previously that the location of the subtropical westerly jet is the strongest control on the frequency of WDs incident on India (Hunt et al., 2018b), so we start by regressing mean model boreal winter (Dec-Mar) zonal wind at $200 \mathrm{hPa}$ against model resolution (measured using the aforementioned grid spacing), and this is shown in Fig. 8. Recalling that a positive coefficient would imply a strengthening of winds under a

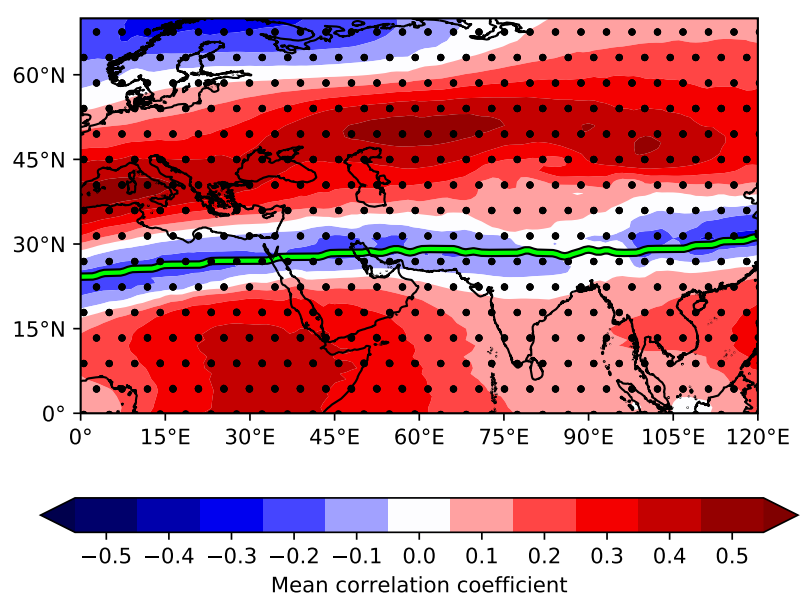

FIG. 8. Correlation of model mean DJFM $200 \mathrm{hPa}$ zonal wind with model grid spacing (as defined in Fig. 6). The climatological winter jet axis (i.e. latitude of greatest $200 \mathrm{hPa}$ zonal wind) computed using ERAInterim is given by the green line. Stippling indicates regions where the correlation is significant at the $90 \%$ confidence level.

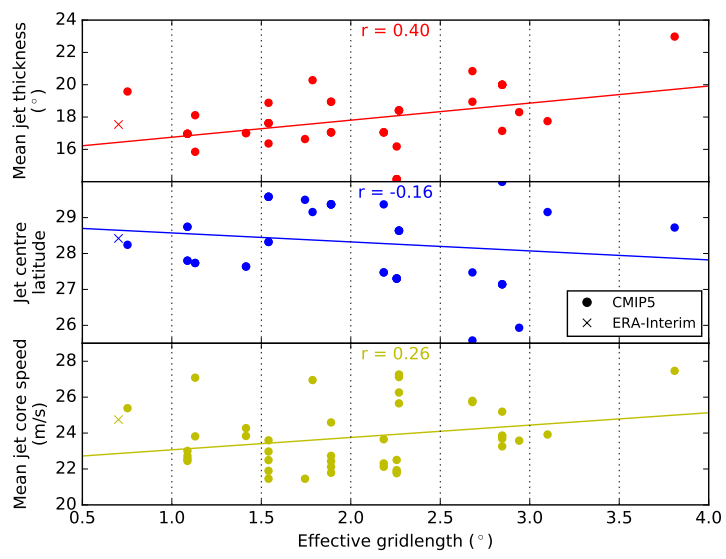

FIG. 9. Mean DJFM subtropical westerly jet statistics for CMIP5 historical experiments and ERA-Interim, computed between $30^{\circ} \mathrm{E}$ and $80^{\circ} \mathrm{E}$, at $200 \mathrm{hPa}$, using zonal wind speed. Top/red: jet thickness, defined as the mean meridional distance between isotachs of $30 \mathrm{~m} \mathrm{~s}^{-1}$; centre/blue: mean latitude of the zonal wind speed centroid, i.e. the centre of the jet; bottom/yellow: mean core speed, i.e. the mean of the highest wind speed at each longitude. Given for each are the trendlines and correlation coefficient for the CMIP5 values.

coarsening of resolution, we note therefore that in lowerresolution models the jet appears slightly weaker (though not significantly so) over central and north India, as well as upstream. Conversely, there are significantly stronger upper-level winds north of $30^{\circ} \mathrm{N}$ in lower-resolution models, across almost the whole continent.

This is most readily interpreted as the jet being climatologically wider in GCMs with a low resolution. To see whether or not this is the case, some mean winter jet statistics were computed for each of the CMIP5 models, as well as ERA-Interim. These are given in Fig. 9, and show the 
relationships between model resolution and jet thickness, location, and core speed, computed over $30^{\circ} \mathrm{E}-80^{\circ} \mathrm{E}$; we see that at a lower resolution the jet is markedly wider, as well as being slightly stronger and positioned at a slightly lower latitude, which is in agreement with Lu et al. (2015). The correlation coefficients for thickness and speed are significantly different from zero at the $90 \%$ confidence level (though the latter is not at $99 \%$ ). With a correlation coefficient of 0.4 , the jet thickness explains more variability than either of the other metrics suggested - consistent with Fig. 8.

\section{b. Biases}

It has been shown both here and in previous literature (Hunt et al., 2018a) that the isopycnal-isobaric angle (shortened here to baroclinic angle) is an important upstream predictor of winter WD frequency in both reanalysis and GCMs. A logical extension to this is to see if there is a bias in the baroclinic angle that can account for the general positive bias in winter WD frequency in GCMs (e.g. Fig. 2). In this section, CMIP5 and ERA-I climatologies are computed for a common time period (1979-2005) to ensure that resulting comparisons are robust. Fig. 10 shows the biases in the winter (DJFM) climatologies of the baroclinic angle, given as a percentage error with respect to the reanalysis. At $500 \mathrm{hPa}$ (Fig. 10(a)), there is a negative bias over most of Asia, except for a zonal belt between about $15^{\circ} \mathrm{N}$ and $20^{\circ} \mathrm{N}$. In that belt, the bias becomes positive, almost reaching $20 \%$ over the north Arabian Sea and north India. Conversely, at $250 \mathrm{hPa}$ (Fig. 10(b)), there is a negative bias (i.e. the GCMs typically make the angle too small) over the entire region of interest; exceeding a $20 \%$ error over much of the domain, though substantially smaller upstream of the Hindu Kush.

At both levels, the areas of most positive bias (excepting some areas of equatorial ocean at $250 \mathrm{hPa}$ ) are found, with similar size and shape, in the same locations as the genesis maxima of Fig. 3(a) and the correlation maxima of Fig. 5. This suggests that because the baroclinic angle is substantially overestimated in the GCM mid-tropospheres, CMIP5 models have a positive bias in winter WD frequency.

Given the previously established relationship between WDs and the subtropical westerly jet both here (Fig. 8) and in previous work (Hunt et al., 2018b), we would be remiss not to examine its representation in CMIP5 models. We apply the definition of $p$ (jet) used by Schiemann et al. (2009), that is:

$$
p_{\text {jet }}= \begin{cases}1 & u>0 \text { and }|\mathbf{u}|>30 \mathrm{~m} \mathrm{~s}^{-1} \\ 0 & \text { otherwise }\end{cases}
$$

This is applied to daily data at $250 \mathrm{hPa}^{9}$ for both reanalysis and model output. Fig. 11 shows the winter climatologies of $p$ (jet) for ERA-I and the CMIP5 MMM; overlaid stippling indicates where the correlation coefficient between the monthly means of $p$ (jet) and the monthly WD frequency is significant. It appears that both the jet, and resulting WD sensitivity are quite well represented in the GCMs; crucially, there is a significant correlation between the location of the jet edges upstream of (and over) India and Pakistan, and in this region the location and gradient of these edges are comparable to reanalysis.

On the balance of evidence presented here, we conclude that the strongest cause of the positive bias in WD frequency and intensity is a positive upstream bias in midtropospheric baroclinic vorticity tendency.

\section{Precipitation}

As discussed in the introduction, some substantial biases in winter precipitation are known to affect this region in CMIP5 models (Palazzi et al., 2013, 2015), particularly over the Himalayan foothills. Fig. 12(a) shows the ratio of climatological winter rainfall in CMIP5 models (19502005) to observed (APHRODITE; 1951-2007). We have presented in this way, as opposed to an absolute difference, because of the large precipitation maximum along the $\mathrm{Hi}$ malayan foothills - wherein a small fractional change of relative unimportance could dwarf much large fractional changes elsewhere.

It is clear that across almost all of India and north Pakistan, there is a marked wet bias, reaching as much as a factor of three in Gujarat. Even poorer is the overestimate of seasonal precipitation over the Tibetan Plateau (n.b. this is where the APHRODITE gauge density is lowest), which is a known issue (Su et al., 2013), and beyond the scope of this study. There is a small area of dry bias, too, in south Pakistan and Afghanistan.

To complete this discussion, we also consider the relationship between ERA-Interim and CMIP5 precipitation (see Fig. 12(b)). We see that only some of the biases from Fig. 12(a) persist: notably the slight positive bias over Gujarat and the significant wet biases at the edge of the Tibetan Plateau. The cause of the former is not clear, but the latter is almost certainly due to inadequate representation of the Tibetan orography at the relatively coarse resolutions of GCMs and reanalyses. It is interesting to note that the positive precipitation bias over the centre of the Tibetan Plateau in CMIP5 models does not persist in ERAInterim, suggesting that the aforementioned representation problem is leading to some larger-scale dynamical bias.

\footnotetext{
${ }^{9}$ Conventionally this is computed at $200 \mathrm{hPa}$, but wind speeds are not available for model outputs at that level at the required temporal resolution.
} 


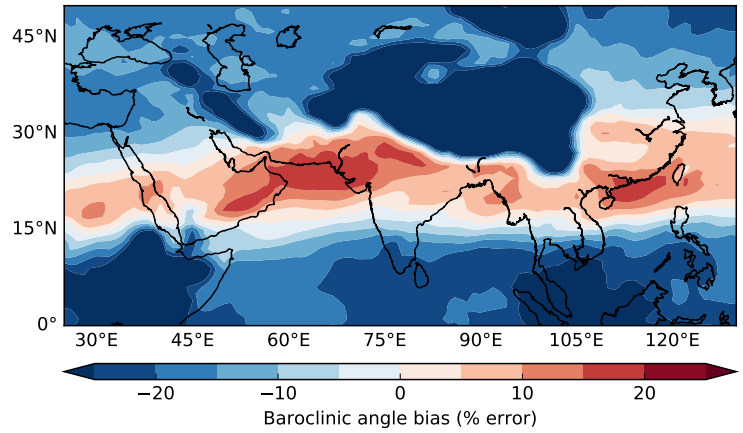

(a) $500 \mathrm{hPa}$

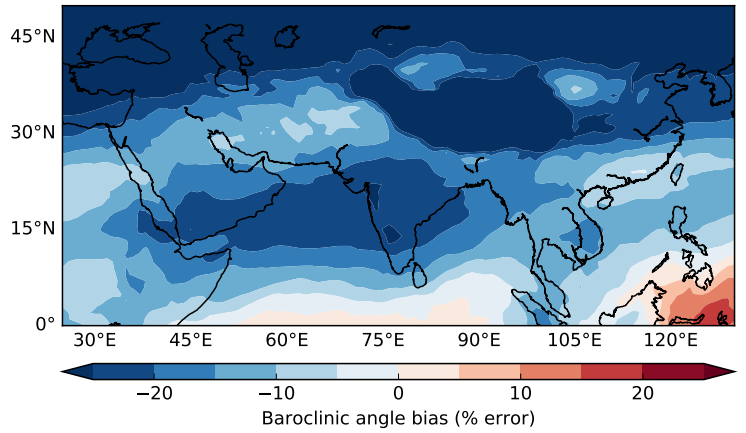

(b) $250 \mathrm{hPa}$

FIG. 10. Percentage error in climatological DJFM baroclinic angle in the CMIP5 multi-model mean, compared with ERA-Interim, at (a) 500 hPa and (b) $250 \mathrm{hPa}$.

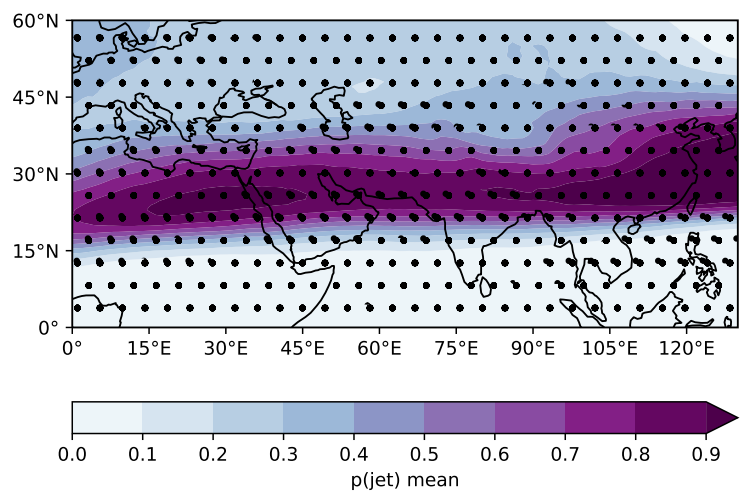

(a) ERA-Interim

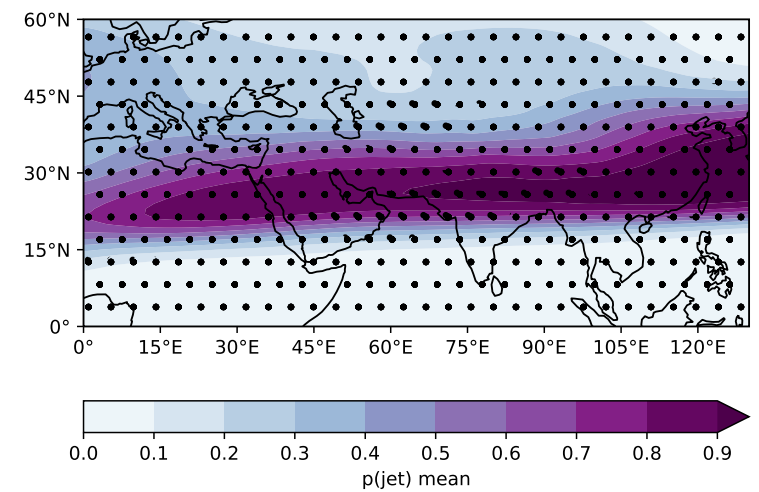

(b) CMIP5

FIG. 11. Climatological winter values of $p$ (jet) at $250 \mathrm{hPa}$ for (a) ERA-Interim and (b) the CMIP5 MMM. Stippling indicates where the correlation coefficient between monthly means of $p$ (jet) and the associated monthly WD frequencies is significantly different from zero at the two-tailed 90\% confidence level, and for CMIP5 where this is true in at least half of the models. In each case, $p$ (jet) is computed on daily data before the relevant means are taken.

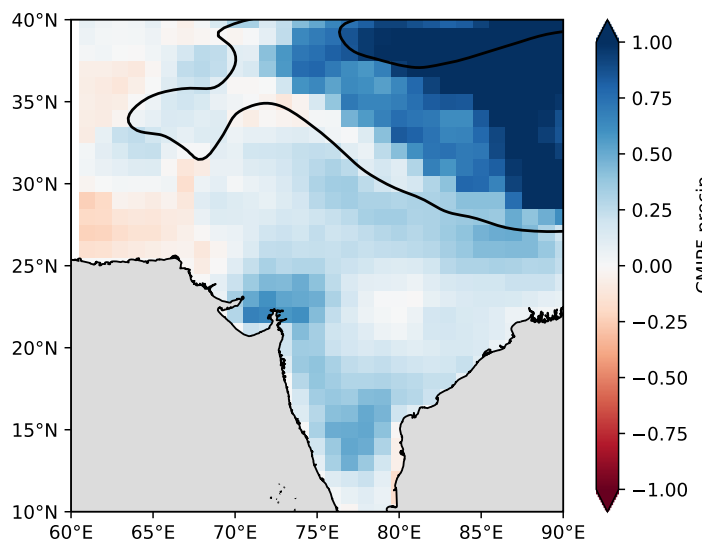

(a) APHRODITE

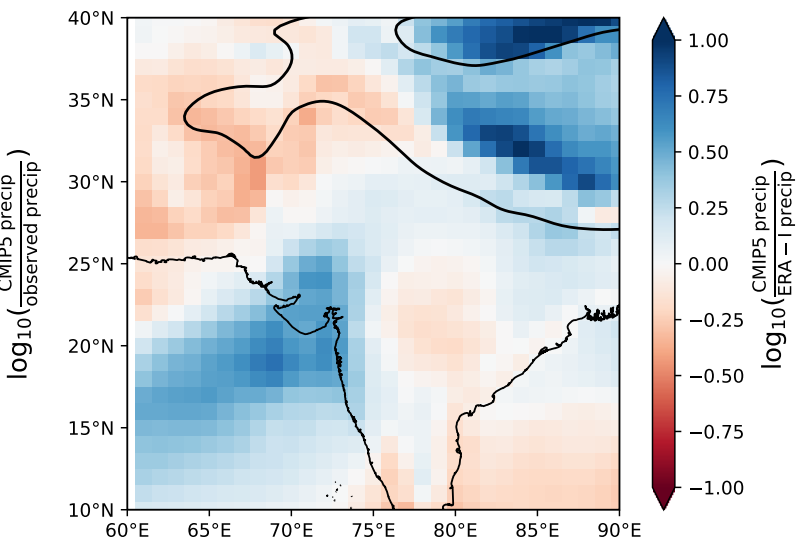

(b) ERA-Interim

FIG. 12. Bias in climatological winter (DJFM) precipitation, computed as the logarithm of the ratio of CMIP5 MMM precipitation and (a) APHRODITE gridded gauge data or (b) ERA-Interim forecast precipitation. Data over oceans are not defined in APHRODITE and are thus not given here. The $2000 \mathrm{~m}$ smoothed isohypse is given in black. 


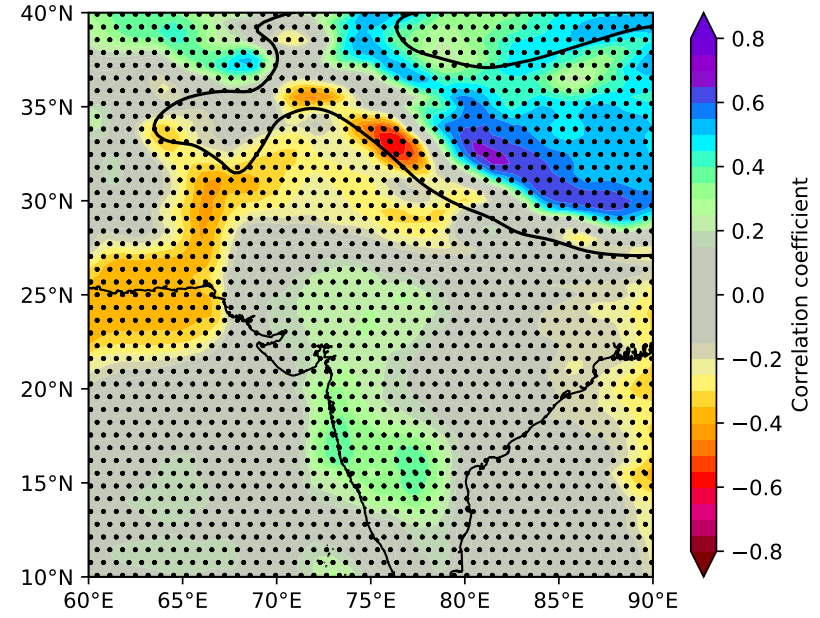

FIG. 13. Correlation coefficient between model grid size and climatological winter (DJFM) precipitation. Model grid size is defined as in Fig. 6, i.e. the geometric mean of longitudinal and latitudinal grid spacings. Stippling indicates where the correlation coefficient is significantly different from zero at the $90 \%$ confidence level. The $2000 \mathrm{~m}$ smoothed isohypse is given in black.

To further explore the relationship between model resolution and precipitation, Fig. 13 shows the correlation coefficient between model grid-spacing (as defined in Fig. 6 and associated text) and climatological DJFM precipitation. Where the correlation value is positive, increasing the model grid spacing will result in increased precipitation (and vice versa for model resolution); we expect WDcaused precipitation to fall into this category, because as we have seen - increased model resolution leads to more populous and more intense WDs. There is a substantial tongue of negative correlation over the head of the Arabian Sea and towards the Hindu Kush, leading into a maximum in the western foothills of the Himalaya. Conversely, across the windward edge of the Himalayas, there is a band of significant positive correlation (that is, increasing model resolution acts to reduce climatological precipitation). It is not clear what causes this, but it is possible the enhanced precipitation upstream - perhaps due to improved resolution of the Himalayan front, increased WD activity, or both - results in less precipitable moisture over the southern Tibetan Plateau. The roles played by moisture transport and larger scale dynamics are significant in WD-generated precipitation (Cannon et al., 2016; Hunt et al., 2018c), and though beyond the scope of this manuscript, should be the subject of future work.

So, to what extent can we attribute these biases to misrepresentation of western disturbances? We have seen already that these GCMs tend to overestimate WD frequency by an average of about $15 \%$ in the winter, and further that they tend to drastically overestimate the intensity, particularly in the tail. We can start to explore this relationship by using simple attribution plots.
Fig. 14(a) shows the climatological winter (DJFM) precipitation that can be attributed to western disturbances using a naïve radius-of-influence approach with tracks from ERA-Interim that are described in Sec. 2d. Simply, we take a fixed radius-of-influence, $800 \mathrm{~km}$, derived from Fig. 11 of Hunt et al. (2018b); then precipitation occurring at a point on a day in which a WD passes within this distance is attributed to that WD. For the CMIP5 case, In areas of northwest India and Pakistan, over $60 \%$ of the winter precipitation occurs in the vicinity of a western disturbance. Of this, about $85 \%$ is provided by the strongest half of systems.

We compute the attribution in the same way for CMIP5 models, before taking the overall mean as shown in Fig. 14(b). The two attribution maps demonstrate a striking similarity. Though the CMIP5 MMM is generally smoother in form, it too has a maximum of almost $70 \%$, and indicates the strong influence of WDs on winter rainfall in Pakistan and north India. Perhaps surprisingly, given the bias shown in Fig. 12, the attribution is wellrepresented along the Himalayan foothills and into the Tibetan Plateau.

What we can deduce from this, therefore, is that the misrepresentation of WDs is responsible for most of the north Indian winter wet bias in CMIP5 models. We cannot state with certainty, however, whether this is due to the intensity bias or the frequency bias, since more intense WDs are correlated with heavier associated precipitation in observations (Hunt et al., 2018b).

To isolate these potential causes is nontrivial. In an inter-model context, resolution exerts a strong control on both WD frequency and intensity; whereas in an intramodel context, upstream baroclinicity causes the same problem. We use the method of partial correlation to disentangle the potential contributions. Consider two variables $x$ and $y$ which potentially have a relationship with a third variable, $z$. Their correlation independent of the influence of $z$ is computed by taking the residuals from their respective linear regressions with $z, \boldsymbol{\delta}_{x}$ and $\boldsymbol{\delta}_{y}$ and instead computing the correlation between these. For our case, where only one variable is to be held constant, the expression for the correlation coefficient has a simple closed form:

$$
\left.\rho(x, y)\right|_{z}=\frac{\rho(x, y)-\rho(x, z) \rho(y, z)}{\sqrt{1-\rho(x, z)^{2}} \sqrt{1-\rho(y, z)^{2}}},
$$

where $\rho$ is the correlation coefficient and the left hand side is evaluated holding $z$ constant. Here, we assign precipitation to $x$ and intensity and frequency interchangeably to $y$ and $z$.

Fig. 15(a) shows the partial correlation between monthly precipitation and monthly WD frequency, holding mean intensity constant. As one would intuitively expect, there is a widespread positive trend; more WDs means more rainfall. The correlation coefficient peaks 


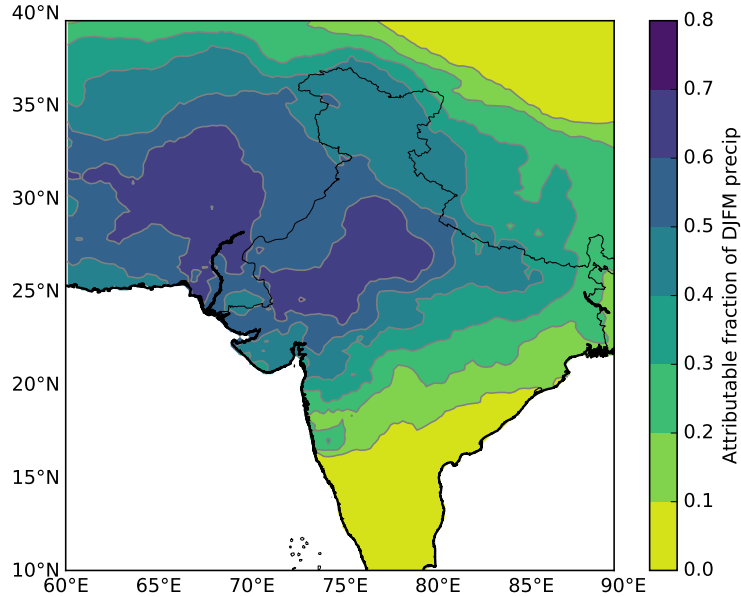

(a) APHRODITE

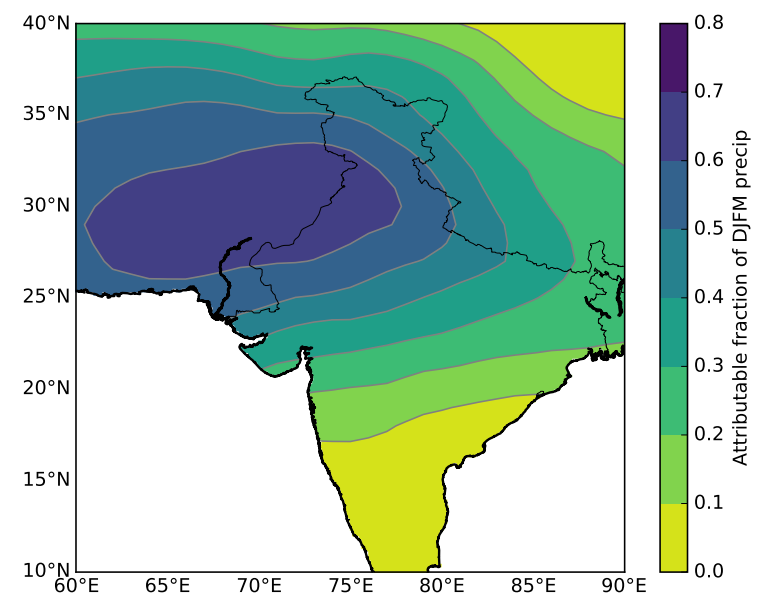

(b) CMIP5 MMM

FIG. 14. Fraction of climatological winter (Dec-Mar) precipitation that can be explained by western disturbance activity. Computed using (a) APHRODITE daily gridded gauge data [1951-2007] and (b) CMIP5 precipitation data [1950-2005]. The attribution (see text) is computed for each model before the mean is taken.

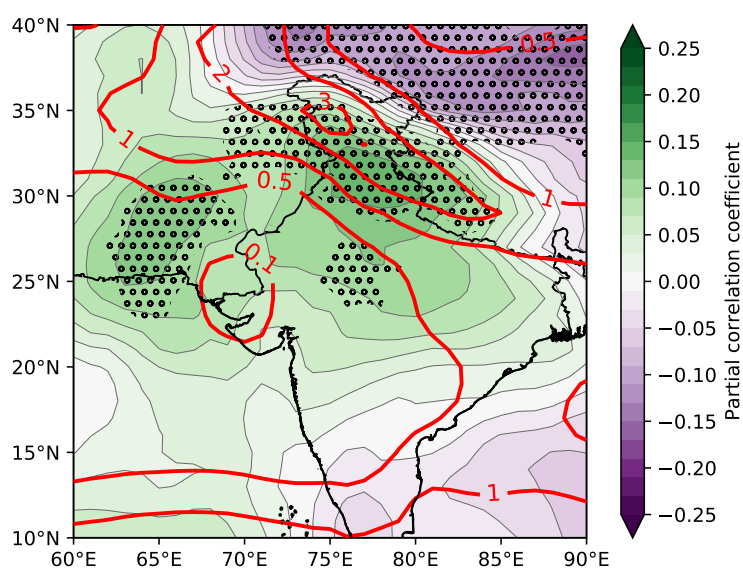

(a) Frequency

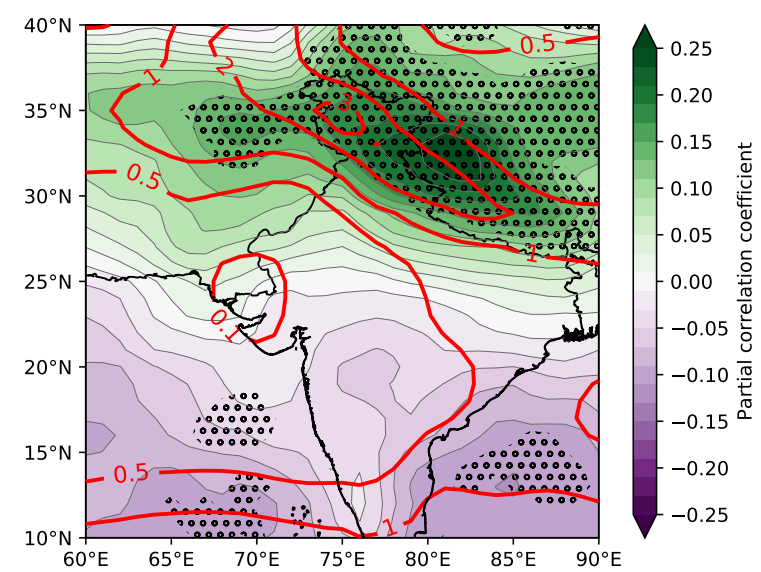

(b) Intensity

FIG. 15. Multi-model mean partial correlation coefficient between winter (DJFM) monthly precipitation and (a) monthly WD frequency and (b) mean monthly peak WD intensity; in each instance holding the other variable constant. Red contours on each indicate the CMIP5 MMM winter precipitation $\left[\mathrm{mm} \mathrm{day}^{-1}\right]$. Stippling indicates where more than half the models indicate a significance exceeding $95 \%$.

over the foothills of the western Himalaya, and is significant almost everywhere, until the sign the the relationship changes to negative over the Bay of Bengal and some parts of the Tibetan Plateau. This pattern is largely in agreement - as it ought to be, to a first order approximation - with Fig. 14(b).

Fig. 15(b) shows the partial correlation between monthly precipitation and monthly mean (peak) intensity, while holding WD frequency constant. Here, the relationship pattern is more striking, there is a dipole whose positive peak is situated at the southwest corner of the Tibetan Plateau and whose negative peak is spread across the Bay of Bengal and Arabian Sea near the south of the peninsula. This implies that during months where the models produce stronger WDs, there is more precipitation being generated over the Himalayas and Tibetan Plateau (and to a lesser extent, over the Hindu Kush and Karakoram). This relationship is partially corroborated by previous work, which shows that stronger western disturbances produce heavier precipitation (Hunt et al., 2018b), and that extreme precipitation events in winter in this region are strongly dependent on meridional moisture flux (Hunt et al., 2018c).

The overall positive bias appears to be related to the overestimation of WD frequency in CMIP5 GCMs, whereas the meridional gradient of that bias (i.e. that it is more positive towards the Himalayan massif) seems to be due to the general overestimation of WD intensity. 


\section{Conclusion and summary}

An assessment of the behaviour of western disturbances (WDs) over 23 CMIP5 models was carried out, with the foci of the investigation being the sources of inter-model and intra-model variability as well as multi-model mean biases against reanalysis. WDs were objectively tracked in the historical (1950-2005) runs of each model, as well as ERA-Interim reanalysis for comparison, using $500 \mathrm{hPa}$ relative vorticity and a domain filter.

Marked variability was found in the climatological WD frequencies between models. These frequencies are strongly anticorrelated with model grid-spacing (i.e. a higher resolution model tends to produce more WDs), with evidence indicating that this is due to coarser models producing a wider subtropical jet that tends to carry disturbances (which are embedded in its northern flank) too far north of India. An alternative explanation is that at lower resolutions the interaction of the jet with the Hindu Kush/Karakoram orography - which is partially responsible for the generation/spin-up of WDs - is increasingly poorly represented.

On average, CMIP5 models tend to slightly overestimate the frequency of WDs. Furthermore, models with higher resolution tend to generate higher-intensity WDs. This effect is particularly pronounced in the tail of the distribution, where the highest resolution models can occasionally create WDs with intensities far higher than those tracked in ERA-Interim reanalysis.

Upstream baroclinic vorticity tendency (baroclinic angle) has previously been shown to be an important contribution to both the genesis and intensification of WDs (Hunt et al., 2018a). Here it has been shown that the spatial covariance of this parameter with downstream WD frequency is represented well in the multi-model statistics in both the mid and upper troposphere. This indicates that the process by which models are spinning up western disturbances is accurate compared to reanalysis, and hence that their gross structures likely follow suit; however, we cannot probe this directly in the multi-model database, since multiple vertical levels are not provided at six-hourly frequency.

There is, however, a large positive bias in midtropospheric baroclinic angle over much of the region where it is significantly correlated with WD frequency. Such a prominent bias is not found in other fields to which WD genesis is sensitive (e.g. proxies of jet location and strength), which indicates that this bias is likely the source of the models' propensity to overestimate WD frequency and intensity.

The most important characteristic of western disturbances, from an impacts point of view, is the winter precipitation associated with them. Using a simple radiusthreshold attribution method, it was shown that WDs bring over $70 \%$ of the climatological winter precipitation to much of north India and Pakistan, and that the spatial attribution pattern is very similar in the CMIP5 MMM climatology. This attribution fraction is not homogeneous, however: it is over $40 \%$ across much of the Hindu-Kush and Himalayan foothills, and as high as 30\% even through into West Bengal. These values indicate just how important a component orographic forcing is in the context of WD precipitation.

Moreover, there exists a marked winter wet bias over South Asia in these GCMs, which could thus, in theory, be linked to the WD frequency bias. Using a novel correlation technique, it was shown that in general this bias can indeed be explained by overestimated WD frequency, and that its spatial variability was more likely explained by simulated WDs having too high an intensity.

One obvious avenue for future work is the exploration of WD characteristics in future climate scenarios; it has been shown here that WDs are sufficiently well represented in CMIP5 models to allow such analysis, and there now exists a tracking framework upon which to base it. However, future studies should be aware of the shortcomings found in this work - most importantly biases in frequency and intensity.

Further work should also seek to frame the results of Sec. 5 in the context of large-scale dynamics and thermodynamics; these, as well as synoptic-scale moisture transport have been shown to be important contributors to the precipitation caused by western disturbances (Cannon et al., 2016; Hunt et al., 2018c). Such work should also seek to attribute precipitation on an event-by-event basis, rather than the statistical approximation we have used, which would allow much deeper analysis of the problems presented here. Furthermore, a detailed analysis on the role of orography and lee cyclogenesis is required to fully understand the impact model resolution has on circulation in this region.

Acknowledgments. KMRH, AGT and LCS are funded by the JPI-Climate and Belmont Forum Climate Predictability and Inter-Regional Linkages Collaborative Research Action via NERC grant NE/P006795/1. We acknowledge the World Climate Research Programmes Working Group on Coupled Modelling,which is responsible for CMIP, and we thank the climate modeling groups for producing and making available their model output. For CMIP the U.S. Department of Energys Program for Climate Model Diagnosis and Intercomparison provides coordinating support and led development of software infrastructure in partnership with the Global Organization for Earth System Science Portals. We thank two anonymous reviewers for their suggestions which have greatly improved the clarity of this manuscript. 


\section{References}

Akhter, J., L. Das, and A. Deb, 2017: CMIP5 ensemble-based spatial rainfall projection over homogeneous zones of India. Climate Dyn., 49 (5-6), 1885-1916.

Camargo, S. J., 2013: Global and regional aspects of tropical cyclone activity in the CMIP5 models. J. Climate, 26 (24), 9880-9902.

Cannon, F., L. M. V. Carvalho, C. Jones, and J. Norris, 2016: Winter westerly disturbance dynamics and precipitation in the western Himalaya and Karakoram: a wave-tracking approach. Theor. Appl. Clim., 125 (1-2), 27-44.

Chitlangia, P. R., 1976: Mean model of western depression. Indian J. Meteor. Geophys., 87 (2), 157-162.

Das, S., 2005: Mountain weather forecasting using MM5 modelling system. Curr. Sci, 88 (6), 899-905.

Dasgupta, M., S. Das, and R. Ashrit, 2004: MM5 3D-Var data assimilation and forecast system over Indian Subcontinent: Results from recent experiments. 5th WRF/14th MM5 Users' Workshop NCAR.

Dee, D. P., and Coauthors, 2011: The ERA-Interim reanalysis: configuration and performance of the data assimilation system. Quart. J. Roy. Meteor. Soc., 137 (656), 553-597, doi:10.1002/qj.828, URL http://dx.doi.org/10.1002/qj.828.

Dimri, A. P., 2004: Impact of horizontal model resolution and orography on the simulation of a western disturbance and its associated precipitation. Meteor. Appl., 11 (2), 115-127.

Dimri, A. P., 2012: Wintertime land surface characteristics in climatic simulations over the western Himalayas. J. Earth. Syst. Sci., 121 (2), 329-344.

Dimri, A. P., and A. Chevuturi, 2014: Model sensitivity analysis study for western disturbances over the Himalayas. Meteor. Atmos. Phys., 123 (3-4), 155-180.

Dimri, A. P., and A. Chevuturi, 2016: Western disturbancesstructure. Western Disturbances-An Indian Meteorological Perspective, Springer, 1-26.

Gong, H., L. Wang, W. Chen, R. Wu, K. Wei, and X.-F. Cui, 2014: The climatology and interannual variability of the East Asian winter monsoon in CMIP5 models. J. Climate, 27 (4), 1659-1678.

Guo, H., S. Chen, A. Bao, J. Hu, A. S. Gebregiorgis, X. Xue, and X. Zhang, 2015: Inter-comparison of high-resolution satellite precipitation products over Central Asia. Remote Sens., 7 (6), 71817211.

Holton, J. R., and G. J. Hakim, 2012: An introduction to dynamic meteorology, Vol. 88. Academic press.

Hunt, K. M. R., J. Curio, A. G. Turner, and R. Schiemann, 2018a: The similarity of western disturbances and Tibetan Plateau vortices. Geophys. Res. Lett., doi:10.1029/2018GL077734, in press.

Hunt, K. M. R., and A. G. Turner, 2017: The representation of Indian monsoon depressions at different horizontal resolutions in the met office unied model. J. Climate, 143 (705), 1756-1771, doi:10.1002/ qj.3030, URL http://dx.doi.org/10.1002/qj.3030.

Hunt, K. M. R., A. G. Turner, and L. C. Shaffrey, 2018b: The evolution, seasonality, and impacts of western disturbances. Quart. J. Roy. Meteor. Soc., 144 (710), 278-290, doi:10.1002/qj.3200.
Hunt, K. M. R., A. G. Turner, and L. C. Shaffrey, 2018c: Extreme daily rainfall in Pakistan and north India: scale-interactions, mechanisms, and precursors. Mon. Wea. Rev., 146 (4), 1005-1022.

Lang, T. J., and A. P. Barros, 2004: Winter storms in the central Himalayas. J. Meteor. Soc. Japan, 82 (3), 829-844.

Levine, R. C., A. G. Turner, D. Marathayil, and G. M. Martin, 2013: The role of northern Arabian Sea surface temperature biases in CMIP5 model simulations and future projections of Indian summer monsoon rainfall. Climate Dyn., 41 (1), 155-172.

Lu, J., G. Chen, L. R. Leung, D. A. Burrows, Q. Yang, K. Sakaguchi, and S. Hagos, 2015: Toward the dynamical convergence on the jet stream in aquaplanet AGCMs. J. Climate, 28 (17), 6763-6782.

Meher, J. K., L. Das, J. Akhter, R. E. Benestad, and A. Mezghani, 2017: Performance of CMIP3 and CMIP5 GCMs to simulate observed rainfall characteristics over the Western Himalayan region. $J$. Climate, 30 (19), 7777-7799.

Mooley, D. A., 1957: The role of western disturbances in the production of weather over India during different seasons. Indian J. Meteor. Geophys., 8, 253-260.

Mull, S., and B. Desai, 1947: The origin and structure of the winter depression of Northwest India. Tech. Rep. 25, India Meteorological Department.

Palazzi, E., J. Hardenberg, and A. Provenzale, 2013: Precipitation in the Hindu-Kush Karakoram Himalaya: Observations and future scenarios. J. Geophys. Res. Atmos., 118 (1), 85-100.

Palazzi, E., J. von Hardenberg, S. Terzago, and A. Provenzale, 2015: Precipitation in the Karakoram-Himalaya: a CMIP5 view. Climate Dyn., 45 (1-2), 21-45.

Patil, R., and P. P. Kumar, 2016: WRF model sensitivity for simulating intense western disturbances over North West India. Model. Earth Sys. Env., 2 (2), 1-15.

Patil, R., and P. P. Kumar, 2017: WRF model sensitivity to initial conditions and study of some important features associated with intense western disturbances over NW India. Int. J. Eng. Tech. Sci. Res., 4 (6).

Prakash, S., and Coauthors, 2015: Seasonal intercomparison of observational rainfall datasets over india during the southwest monsoon season. Int. J. Climatol., 35 (9), 2326-2338.

Purich, A., T. Cowan, W. Cai, P. van Rensch, P. Uotila, A. Pezza, G. Boschat, and S. Perkins, 2014: Atmospheric and oceanic conditions associated with Southern Australian heat waves: A CMIP5 analysis. J. Climate, 27 (20), 7807-7829.

Rakesh, V., R. Singh, D. Yuliya, P. K. Pal, and P. C. Joshi, 2009: Impact of variational assimilation of modis thermodynamic profiles in the simulation of western disturbance. Int. J. Remote Sens., 30 (18), 4867-4887.

Ramanathan, V., and K. R. Saha, 1972: Application of a primitive equation barotropic model to predict movement of Western Disturbances. J. Appl. Meteor., 11 (2), 268-272.

Rangachary, N., and B. K. Bandyopadhyay, 1987: An analysis of the synoptic weather pattern associated with extensive avalanching in Western Himalaya. Int. Assoc. of Hydrol. Sci. Publ, 162, 311-316. 
Ridley, J., A. Wiltshire, and C. Mathison, 2013: More frequent occurrence of westerly disturbances in Karakoram up to 2100. Science of The Total Environment, 468, S31-S35.

Roberts, M. J., and Coauthors, 2015: Tropical cyclones in the UPSCALE ensemble of high-resolution global climate models. J. Climate, 28 (2), 574-596, doi:10.1175/JCLI-D-14-00131.1, URL http: //dx.doi.org/10.1175/JCLI-D-14-00131.1.

Sandeep, S., R. S. Ajayamohan, W. R. Boos, T. P. Sabin, and V. Praveen, 2018: Decline and poleward shift in Indian summer monsoon synoptic activity in a warming climate. Proc. Natl. Acad. Sci. (USA), 115 (11), 2681-2686.

Schiemann, R., D. Lüthi, and C. Schär, 2009: Seasonality and interannual variability of the westerly jet in the Tibetan Plateau region. $J$. Climate, 22 (11), 2940-2957.

Semwal, G., and A. P. Dimri, 2012: Impact of initial and boundary conditions on simulations of western disturbances and associated precipitation. Nat. Hazards, 64 (2), 1405-1424.

Semwal, G., and R. K. Giri, 2007: Precipitation simulation of synoptic scale systems over western Himalayan region using Advanced Regional Prediction System (ARPS) model. Mausam, 58 (4), 471.

Serra, Y. L., and K. Geil, 2017: Historical and projected eastern Pacific and Intra-Americas sea TD-wave activity in a selection of IPCC AR5 models. J. Climate, 30 (7), 2269-2294.

Sperber, K. R., H. Annamalai, I.-S. Kang, A. Kitoh, A. Moise, A. G. Turner, B. Wang, and T. Zhou, 2013: The Asian summer monsoon: an intercomparison of CMIP5 vs. CMIP3 simulations of the late 20th century. Climate Dyn., 41 (9-10), 27112744, doi:10.1007/s00382-012-1607-6, URL http://dx.doi.org/10. 1007/s00382-012-1607-6.

Su, F.-G., X.-L. Duan, D.-L. Chen, Z.-C. Hao, and L. Cuo, 2013: Evaluation of the global climate models in the CMIP5 over the Tibetan Plateau. J. Climate, 26 (10), 3187-3208.

Taylor, K. E., R. J. Stouffer, and G. A. Meehl, 2012: An overview of CMIP5 and the experiment design. Bull. Amer. Meteor. Soc., 93 (4), 485-498.

Thomas, L., S. K. Dash, and U. C. Mohanty, 2014: Influence of various land surface parameterization schemes on the simulation of Western Disturbances. Meteor. Appl., 21 (3), 635-643.

Thomas, L., S. K. Dash, U. C. Mohanty, and C. A. Babu, 2017: Features of western disturbances simulated over north india using different land-use data sets. Meteor. Appl., doi:10.1002/met.1687.

Tiwari, P. R., S. C. Kar, U. C. Mohanty, S. Kumari, P. Sinha, A. Nair, and S. Dey, 2014: Skill of precipitation prediction with GCMs over north India during winter season. Int. J. Climatol., 34 (12), 34403455 .

Walsh, K., S. Lavender, E. Scoccimarro, and H. Murakami, 2013: Resolution dependence of tropical cyclone formation in CMIP3 and finer resolution models. Climate Dyn., 40 (3-4), 585-599.

Yadav, R. K., K. R. Kumar, and M. Rajeevan, 2012: Characteristic features of winter precipitation and its variability over northwest India. J. Earth. Syst. Sci., 121 (3), 611-623.

Yatagai, A., O. Arakawa, K. Kamiguchi, H. Kawamoto, M. I. Nodzu, and A. Hamada, 2009: A 44-year daily gridded precipitation dataset for Asia based on a dense network of rain gauges. Sola, 5, 137-140.
Yatagai, A., K. Kamiguchi, O. Arakawa, A. Hamada, N. Yasutomi, and A. Kitoh, 2012: APHRODITE: Constructing a long-term daily gridded precipitation dataset for Asia based on a dense network of rain gauges. Bull. Amer. Meteor. Soc., 93, 1401-1415, doi:10.1175/BAMS-D-11-00122.1, URL http://dx.doi.org/10.1175/ BAMS-D-11-00122.1.

Yianilos, P. N., 1993: Data structures and algorithms for nearest neighbor search in general metric spaces. SODA, Vol. 93, 311-21.

Zappa, G., L. C. Shaffrey, and K. I. Hodges, 2013a: The ability of CMIP5 models to simulate north atlantic extratropical cyclones. $J$. Climate, 26 (15), 5379-5396.

Zappa, G., L. C. Shaffrey, K. I. Hodges, P. G. Sansom, and D. B. Stephenson, 2013b: A multimodel assessment of future projections of North Atlantic and European extratropical cyclones in the CMIP5 climate models. J. Climate, 26 (16), 5846-5862. 